\title{
ПРОЦЕССЫ ЗДОРОВЬЯ И БОЛЕЗНЕЙ В РЕГИОНЕ АМАЗОНКИ: ФАКТОРЫ ОКРУЖАЮЩЕЙ СРЕДЫ И ПОЯВЛЕНИЕ БОЛЕЗНЕЙ
}

\section{ОБЗОРНАЯ СТАТЬЯ}

CUSTÓDIO, Wenderson Picanço ${ }^{1}$, CHAVES, Juliana Vitória Rocha Leite ${ }^{2}$, PANTOJA, Patrícia Trindade ${ }^{3}$, CÁRDENAS, Anneli Mercedes Celis de ${ }^{4}$, ANDRADE, Rosemary Ferreira $\mathrm{de}^{5}$, DAPUREZA, Demilto Yamaguchi ${ }^{6}$, FECURY, Amanda Alves ${ }^{7}$

\section{CUSTÓDIO, Wenderson Picanço. и др. Процессы здоровья и болезней в}

регионе Амазонки: фракторы окружающей среды и появление болезней.

Revista Científica Multidisciplinar Núcleo do Conhecimento. Год. 06, Изготовить. 12, Vol. 03, стр. 05-21. Декабрь 2021 года. ISSN: 2448-0959, Ссылка доступа: https://www.nucleodoconhecimento.com.br/здравоохранение/появление-болезней,

DOI: 10.32749/nucleodoconhecimento.com.br/ru/104519

\footnotetext{
${ }^{1}$ Степень магистра в области медицинских наук Федерального университета Амапа; Специалист по гематологии Бразильского союза колледжей; Степень бакалавра в области биомедицины фракультета Макапа; Окончил педагогический фракультет Городского университета Сан-Паулу; Окончил Университет биологических наук города Сан-Паулу. ORCID: 0000-00030424-6852.

${ }^{2}$ Студент магистратуры по медицинским наукам Федерального университета Амапа; Аспирантура по детской стоматологии Группы стоматологических специальностей; Аспирантура по стоматологии для больных раком Сирийской ливанской больницы; Степень в области стоматологии фракультета Макапа - FAMA. ORCID: 0000-0002-7595-9094.

${ }^{3}$ Студент магистратуры по медицинским наукам Федерального университета Амапа; Аспирантура по неотложной и неотложной помощи и отделение интенсивной терапии из колледжа Мадре Тереза-FAMAT; Аспирантура в области преподавания и управления высшим образованием в колледже Fatec; Окончил фракультет сестринского дела Макапа - FAMA. ORCID: 0000-0002-8667-0165.

${ }^{4}$ Доктор фрилософии в области сестринского дела, Школа сестринского дела, Университет СанПаулу EEUSP, магистр фундаментального сестринского дела, Университет Сан-Паулу EEUSP. Окончила фракультет сестринского дела в Национальном университете Кальяо в Лиме, Перу. ОРСИД: https://orcid.org/0000-0002-6581-4326.

${ }^{5}$ Окончила Факультет сестринского дела и акушерства Государственного университета Пара (UEPA), степень магистра сестринского дела (UFPA) и доктора философии в области наук: социально-экологическое развитие (NAEA/UFPA). В настоящее время он является профессором Федерального университета Амапа. Он развивает работы по следующим темам: общественное здравоохранение, эпидемиология, амапа, Амазонка, малярия и миграция. ОРСИД: https://orcid.org/0000-0003-4472-8565.

${ }^{6}$ Кандидат наук, магистр физического воспитания и окончил фракультет физического воспитания. ОРСИД: https://orcid.org/0000-0001-8336-2178.

${ }^{7} \mathrm{PhD}$ и степень магистра в области тропических болезней, специалист в области микробиологии, биомедицинского ORCID: http://orcid.org/0000-0001-5128-8903.

RC: 104519
}

Ссылка доступа: https://www.nucleodoconhecimento.com.br/здравоохранение/появлениеболезней 


\section{СВОДКА}

Введение: Амазонка всегда была объектом многочисленных исследований, посвященных окружающей среде, обществу и здоровью. Наводящий вопрос: какие фракторы окружающей среды способствуют возникновению болезней в регионе Амазонки? Цель: подход основные фракторы окружающей среды, способствующие возникновению болезней в регионе Амазонки Метод: это обзор литературы в базах данных Scientific Electronic Library Online (SciELO), US National Library of Medicine National Institutes of Health (PubMeD), Виртуальная библиотека здоровья (VHL) В и Национальный институт космических исследований (INPE) общей сложности при построении исследования было использовано 18 статей, каждая из которых прошла через критерии включения и исключения, установленные для фрильтрации только журналов с подходами к теме. Результаты. С эпидемиологической точки зрения, пространство Амазонки, образованное взаимодействием социально-экологической системы, отличается от других частей страны характеристиками. Это различие вызвано естественной экологической основой и формами проживания и развития. Вывод: основными экологическими факторами, способствующими возникновению болезней в регионе Амазонки, являются вырубка лесов, пожары, загрязнение рек, процесс урбанизации и агробизнес.

Ключевые слова: здоровье-болезнь, Амазонка, фракторы окружающей среды.

\section{1. ВСТУПЛЕНИЕ}

Амазонка всегда была предметом многочисленных исследований, посвященных ее окружающей среде, обществу и развитию. В публикациях последних десятилетий обсуждались важные региональные аспекты, такие как биоразнообразие, землепользование, наука и техника,_рост городов (BROWDER в GODFREY, 2017), устойчивое развитие и проекты развития, вызывающие обезлесение (PERZ, 2002). 
Чтобы понять сложность Амазонки по отношению к различным регионам мира, важно помнить, что эта сложность не ограничивается ее биологическими и экологическими характеристиками, а связана с тем, как население, населяющее ее, отличается по своему образу жизни и по образу действий и мышления (ROLIM, 2015).

Концепция здоровья-болезни может принимать региональное измерение, поскольку в этом регионе существует огромный пробел в научной информации о социальных и экологических условиях, чтобы удовлетворить потребности общества. Следует отметить, что в этом регионе наблюдается высокая концентрация людей, закрепленных в городских центрах, особенно в столицах, что вызывает широко распространенные проблемы в крупных центрах, таких как: отсутствие очищенной воды и основных санитарных условий, распространение насекомых-переносчиков болезней, анофелиновые передатчики передающий малярию, денге и другие (CAÑETE в RAVENA-CAÑETE, 2010).

Выбор этого региона в качестве объекта анализа обосновывается его экологическими (климат, экосистемы и биоразнообразие) и демографическими (социальное разнообразие с низкой плотностью населения и концентрацией в городах), которые в сочетании с экономическими процессами, такими как экстенсивное сельское хозяйство, животноводство, добыча полезных ископаемых, гидроэнергетика и промышленность, влияют на здоровье населения согласно его модели развития. Исходя из этого, главный вопрос исследования: какие фракторы окружающей среды способствуют возникновению заболеваний в регионе Амазонки?

Таким образом, цель этого исследования состояла в том, чтобы подчеркнуть экологические фракторы, которые способствуют возникновению заболеваний в регионе Амазонки, а также подчеркнуть исследования, направленные на регион, что позволило бы создать более широкую библиографическую коллекцию по этой теме, помимо подчеркивания необходимости создания и изменения 
политики общественного здравоохранения для населения, проживающего в этом регионе.

\section{2. МЕТОДОЛОГИЯ}

Эта работа проводилась посредством обзора литературы в научных журналах, доступных на веб-сайтах и базах данных: Scielo, pubmed, Virtual Health Library и исследованиях, проводимых Национальным институтом космических исследований. Поиск по статьям проводился в период с августа по ноябрь 2021 года, и было собрано 18 статей, и все они были отобраны для построения исследования. Критериями включения стали статьи, опубликованные с 2000 по 2021 год на английском, испанском и португальском языках. С другой стороны, критериями исключения были статьи, опубликованные до 2000 года, дубликаты, редакционные статьи письма редактора, а также журналы на языках, отличных от тех, которые упомянуты в критериях включения. Дескрипторами, используемыми для поиска исследований, были: Здоровье-болезнь; Амазонка; Факторы окружающей среды.

Таким образом, данная статья представляет собой анализ процесса здоровьязаболевания в регионе Амазонки и факторов окружающей среды, влияющих на возникновение заболеваний (социальные, экономические, культурные и экологические фракторы, а также другие фракторы, влияющие на возникновение проблем со здоровьем у населения), по данным Sobral and Freitas (2010) с использованием количественных переменных (показателей) и обзора литературы.

\section{3. РЕЗУЛЬТАТЫ}

Таблица 1. Лучшие результаты избранных статей для исследования

\begin{tabular}{|l|l|l|l|}
\hline Титул & Авторы, год & Основные результаты \\
издания $\quad$ и & \\
страна & \\
\hline
\end{tabular}

RC: 104519

Ссылка доступа: https://www.nucleodoconhecimento.com.br/здравоохранение/появлениеболезней 


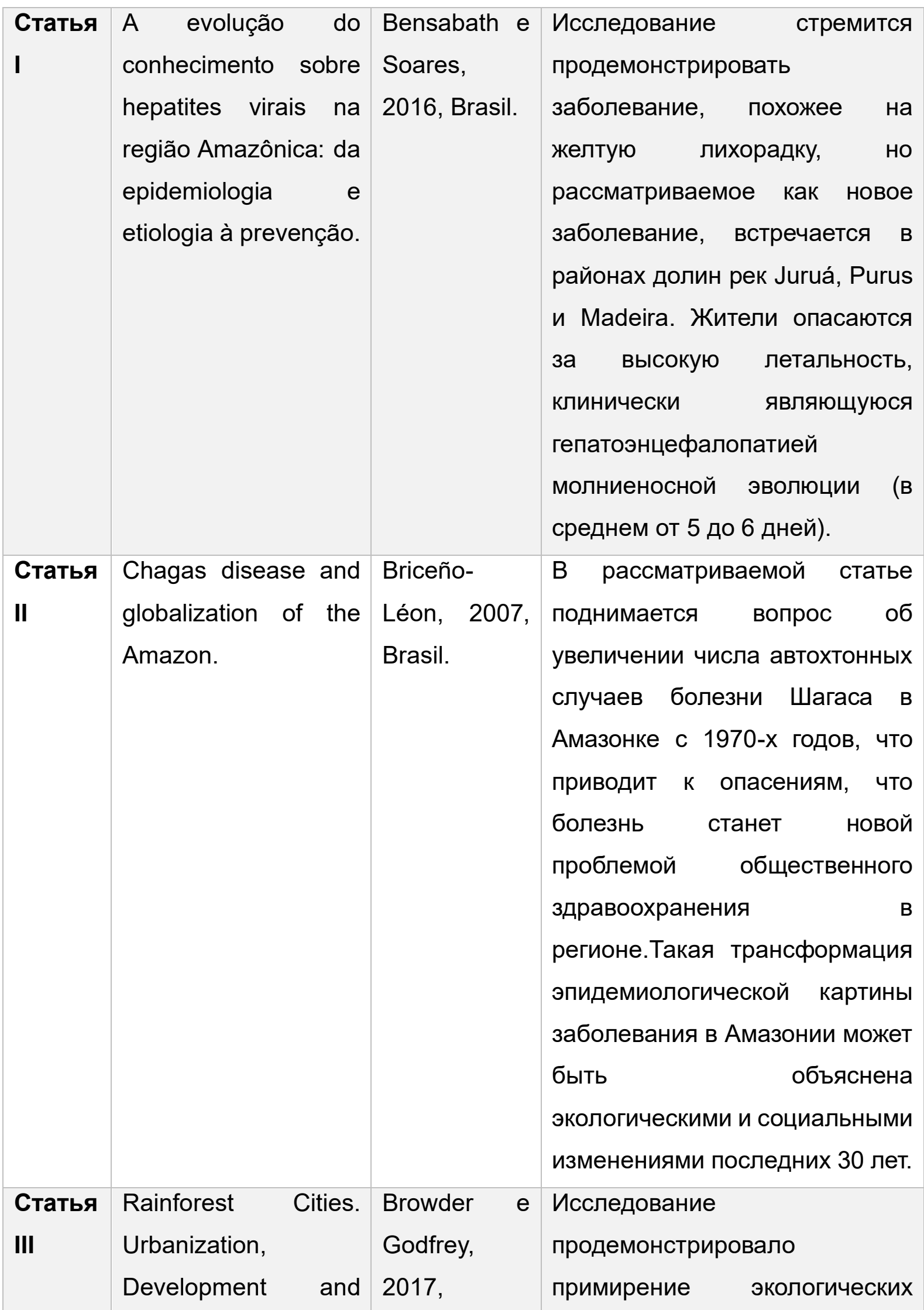

RC: 104519

Ссылка доступа: https://www.nucleodoconhecimento.com.br/здравоохранение/появлениеболезней 


\begin{tabular}{|c|c|c|c|}
\hline & $\begin{array}{l}\text { Colonization of the } \\
\text { Brazilian Amazon. }\end{array}$ & $\begin{array}{l}\text { Estados } \\
\text { Unidos. }\end{array}$ & \begin{tabular}{lrr} 
проблем перед & лицом \\
нынешней & глобальной \\
урбанизации & с & учетом \\
интенсивного & \multicolumn{2}{c}{ городского } \\
перехода, происходящего в \\
регионе Амазонки.
\end{tabular} \\
\hline $\begin{array}{l}\text { Статья } \\
\text { IV }\end{array}$ & $\begin{array}{l}\text { Populações } \\
\text { Tradicionais } \\
\text { Amazônicas: } \\
\text { revisando conceitos. }\end{array}$ & $\begin{array}{l}\text { Cañete e } \\
\text { Ravena- } \\
\text { Cañete, } \\
\text { 2010, Brasil. }\end{array}$ & 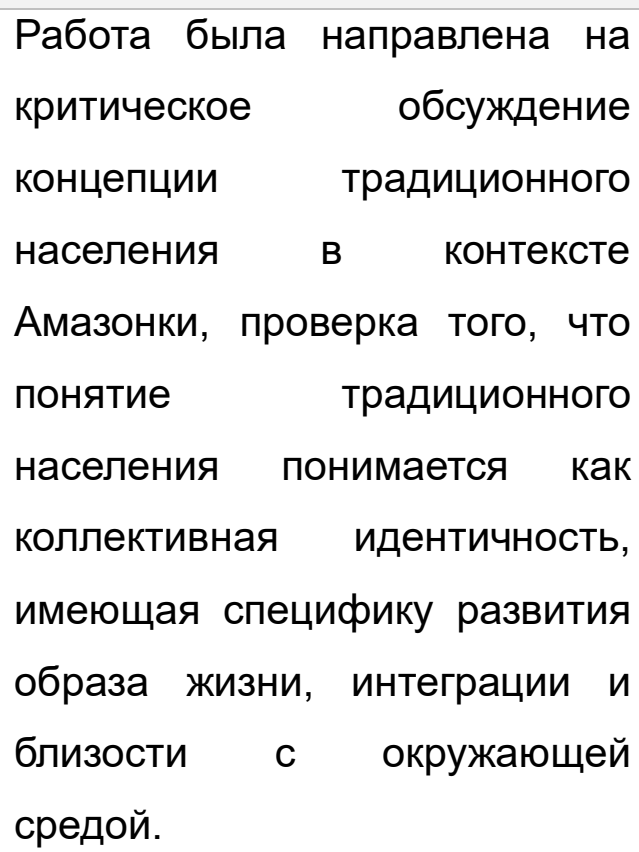 \\
\hline $\begin{array}{l}\text { Статья } \\
\text { V }\end{array}$ & $\begin{array}{l}\text { O trabalho como } \\
\text { determinante } \\
\text { processo do } \\
\text { doença. }\end{array}$ & $\begin{array}{l}\text { Cardoso, } \\
\text { 2015, Brasil. }\end{array}$ & 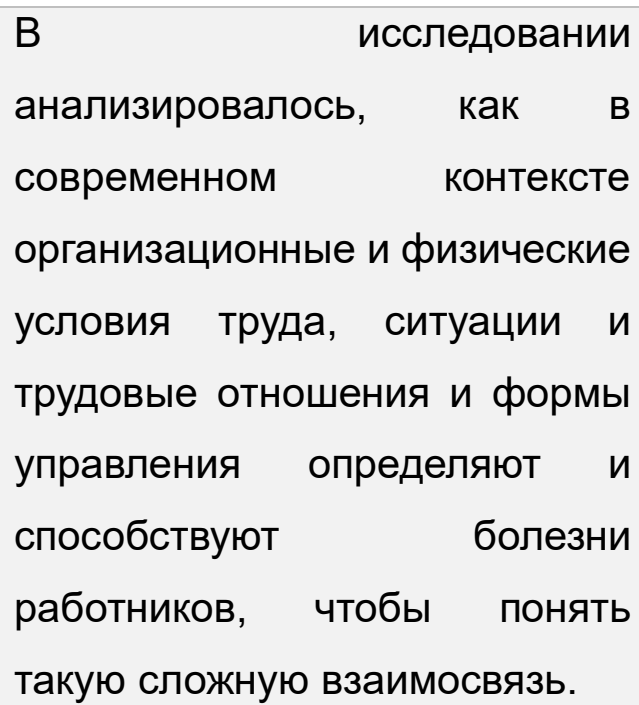 \\
\hline $\begin{array}{l}\text { Статья } \\
\text { VI }\end{array}$ & $\begin{array}{l}\text { Determinante da } \\
\text { saúde no Brasil: a } \\
\text { procura da equidade }\end{array}$ & $\begin{array}{l}\text { Carrapato et } \\
\text { al., } 2017, \\
\text { Brasil. }\end{array}$ & $\begin{array}{l}\text { Настоящее исследование } \\
\text { направлено на выявление с } \\
\text { помощью библиометрии того, }\end{array}$ \\
\hline
\end{tabular}




\begin{tabular}{|c|c|c|c|}
\hline & na saúde. & & 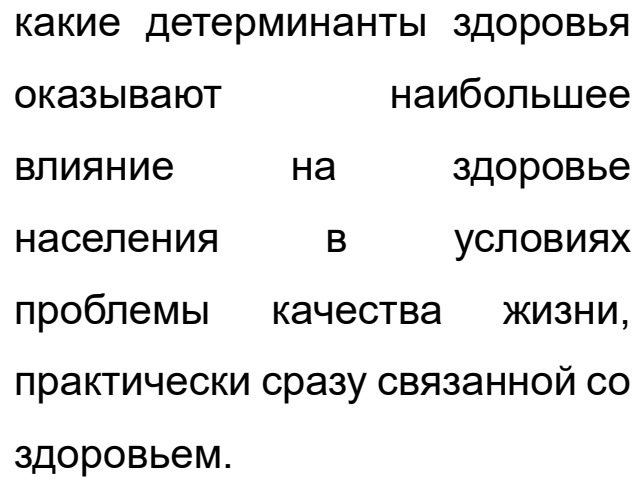 \\
\hline $\begin{array}{l}\text { Статья } \\
\text { VII }\end{array}$ & $\begin{array}{l}\text { The Health of } \\
\text { Indigenous Peoples in } \\
\text { the Brazilian Amazon. }\end{array}$ & $\begin{array}{l}\text { Confalonieri, } \\
2000, \\
\text { Amsterdam. }\end{array}$ & $\begin{array}{l}\text { Целью статьи было } \\
\text { продемонстрировать } \\
\text { эпидемические заболевания и } \\
\text { разрушение окружающей } \\
\text { среды многих племен, которые } \\
\text { перешли от контакта к } \\
\text { перемещению, уничтожению и } \\
\text { вымиранию за одно поколение, } \\
\text { а также декультурация и } \\
\text { строительство крупных } \\
\text { проектов развития и то, как они } \\
\text { оказали катастрофические } \\
\text { последствия для коренного } \\
\text { населения Амазонки. }\end{array}$ \\
\hline $\begin{array}{l}\text { Статья } \\
\text { VIII }\end{array}$ & $\begin{array}{l}\text { Saúde na Amazônia: } \\
\text { um modelo conceitual } \\
\text { para a análise de } \\
\text { paisagens e doenças. }\end{array}$ & $\begin{array}{l}\text { Confalonieri, } \\
\text { 2005, Brasil. }\end{array}$ & $\begin{array}{l}\text { В исследовании был } \\
\text { рассмотрен } \\
\text { эпидемиологический профиль } \\
\text { населения Амазонки в связи с } \\
\text { социально-экологической } \\
\text { динамикой региона } \\
\text { разработана концептуальная } \\
\text { модель анализа, которая } \\
\text { включает в себя три основные } \\
\text { категории ландшафтов }\end{array}$ \\
\hline
\end{tabular}

RC: 104519

Ссылка доступа: https://www.nucleodoconhecimento.com.br/здравоохранение/появлениеболезней 


\begin{tabular}{|c|c|c|c|}
\hline & & & $\begin{array}{l}\text { Амазонии: природные, } \\
\text { антропизированные } \\
\text { построенные. }\end{array}$ \\
\hline $\begin{array}{l}\text { Статья } \\
\mathrm{IX}\end{array}$ & $\begin{array}{l}\text { Indicadores de } \\
\text { sustentabilidade } \\
\text { ambiental e de saúde } \\
\text { na Amazônia Legal. }\end{array}$ & $\begin{array}{l}\text { Freitas } \\
\text { Giatti, 2009, } \\
\text { Brasil. }\end{array}$ & 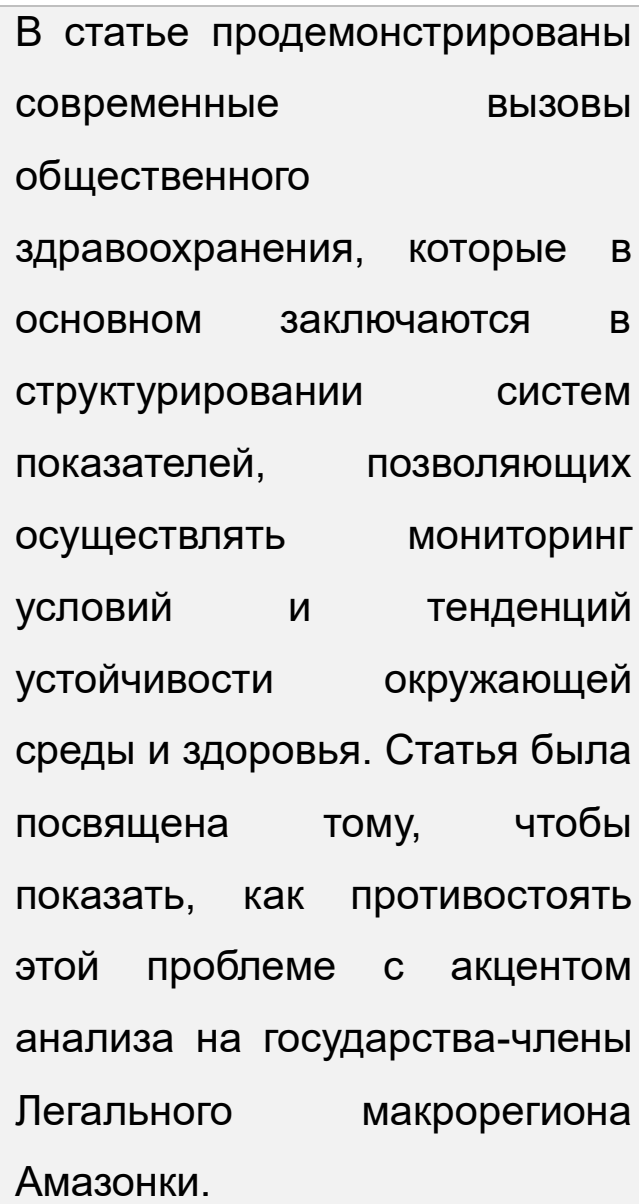 \\
\hline $\begin{array}{l}\text { Статья } \\
\mathbf{X}\end{array}$ & $\begin{array}{l}\text { Custo das doenças } \\
\text { atribuíveis a fatores } \\
\text { ambientais na cidade } \\
\text { de Manaus, } \\
\text { Amazonas, Brasil. }\end{array}$ & $\begin{array}{l}\text { Medeiros, } \\
\text { 2014, Brasil. }\end{array}$ & 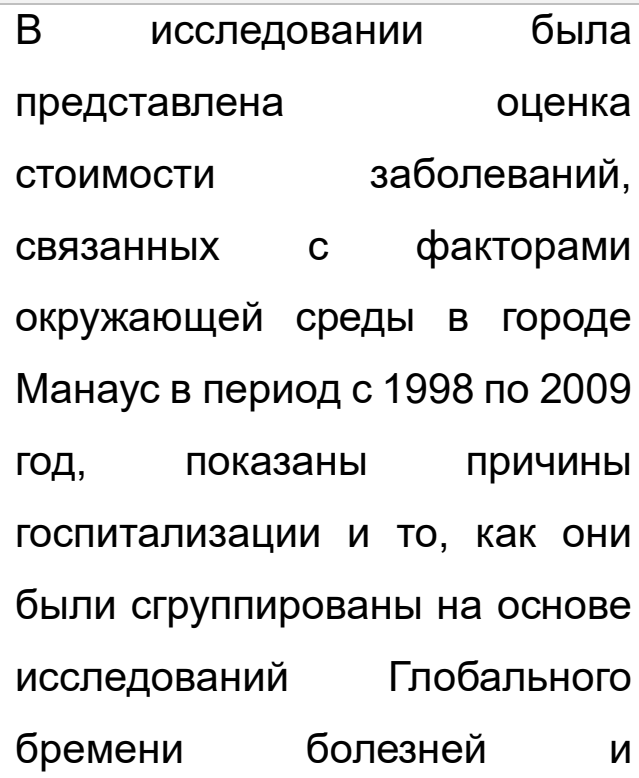 \\
\hline
\end{tabular}

RC: 104519

Ссылка доступа: https://www.nucleodoconhecimento.com.br/здравоохранение/появлениеболезней 


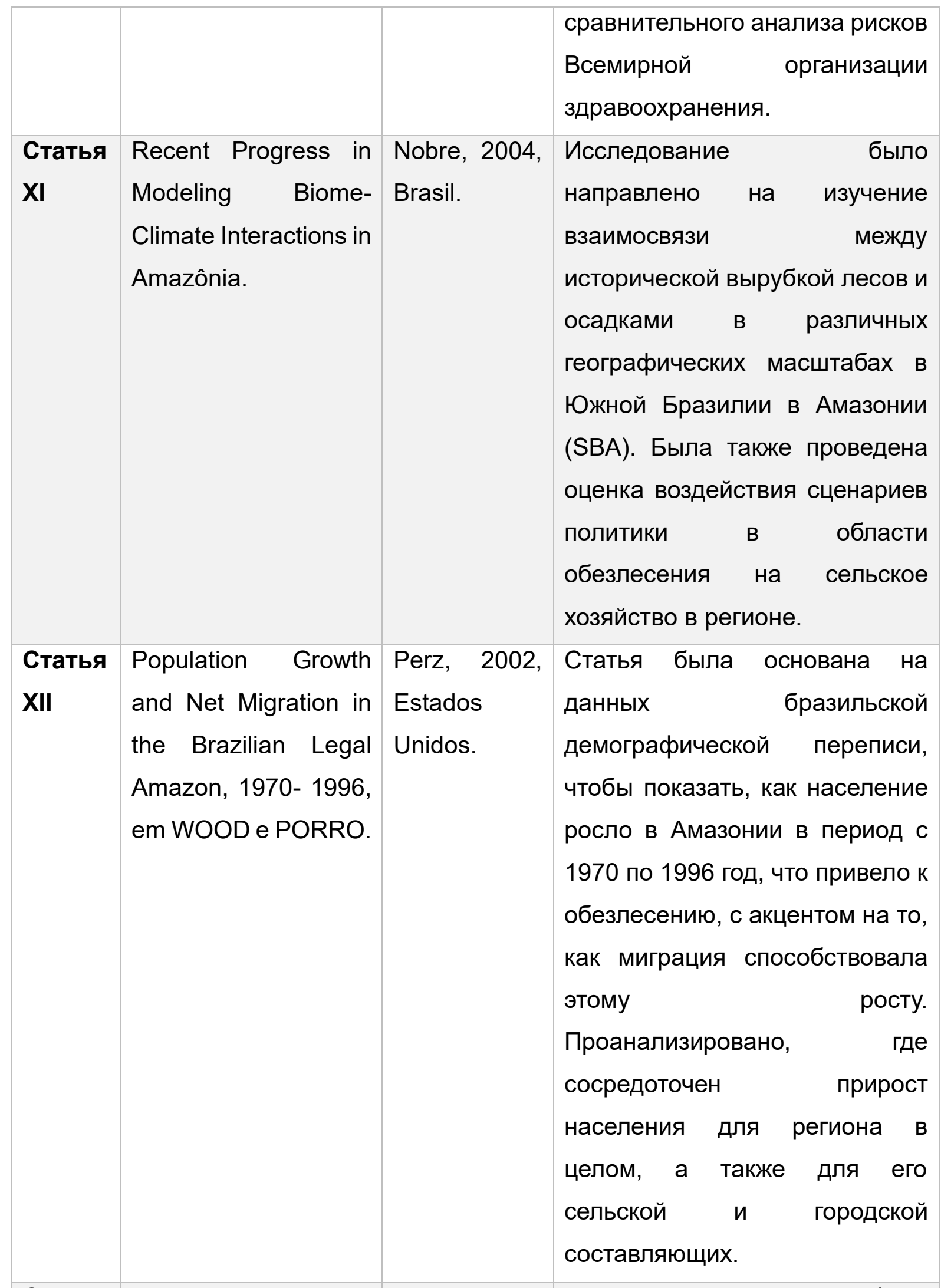

Статья Estudo dos arbovirus Rodrigues, Исследование было 


\begin{tabular}{|c|c|c|c|}
\hline XIII & $\begin{array}{l}\text { na Amazônia } \\
\text { Brasileira. }\end{array}$ & 2004, Brasil. & $\begin{array}{l}\text { направлено на обзор эко } \\
\text { эпидемиологических аспектов, } \\
\text { представленных Св. Луи (SLE), } \\
\text { Восток (ЕEA), Запад (WEE) и } \\
\text { венесуэльский } \\
\text { энцефралит, [subtipos III, } \\
\text { Мucambo (MUC) е IV, Pixuna } \\
\text { (РІХ)] полученный в результате } \\
\text { исследований, проведенных в } \\
\text { нескольких районах } \\
\text { бразильского региона } \\
\text { Амазонки, особенно вдоль } \\
\text { автомагистралей и проектов } \\
\text { развития. }\end{array}$ \\
\hline $\begin{array}{l}\text { Статья } \\
\text { XIV }\end{array}$ & $\begin{array}{l}\text { A pobreza e a riqueza } \\
\text { na região amazônica } \\
\text { e a contribuição da } \\
\text { política de assistência } \\
\text { social: o estado do } \\
\text { amazonas em foco. }\end{array}$ & $\begin{array}{l}\text { Rolim, 2015, } \\
\text { Brasil. }\end{array}$ & $\begin{array}{l}\text { В статье рассматриваются } \\
\text { противоречия между } \\
\text { бедностью и богатством и } \\
\text { вклад политики социальной } \\
\text { помощи в штате Амазонас. В } \\
\text { результате она показала, что } \\
\text { нынешний Манаус, столица } \\
\text { государства, сосуществует с } \\
\text { противоречиями нового } \\
\text { капиталистического порядка, } \\
\text { где визуализируется } \\
\text { сопоставление богатства и } \\
\text { бедности. }\end{array}$ \\
\hline $\begin{array}{l}\text { Статья } \\
\mathrm{XV}\end{array}$ & $\begin{array}{l}\text { Modelo de } \\
\text { organização de } \\
\text { indicadores para } \\
\text { operacionalização }\end{array}$ & $\begin{array}{l}\text { Sobral e } \\
\text { Freitas, 2010, } \\
\text { Brasil. }\end{array}$ & $\begin{array}{l}\text { В ходе исследования были } \\
\text { проверены } \\
\text { детерминанты и их связь с } \\
\text { процессом }\end{array}$ \\
\hline
\end{tabular}




\begin{tabular}{|c|c|c|c|}
\hline & $\begin{array}{l}\text { dos determinantes } \\
\text { socioambientais da } \\
\text { saúde. }\end{array}$ & & $\begin{array}{l}\text { здоровьем и болезнями между } \\
\text { различными группами } \\
\text { населения и их большое } \\
\text { значение для общественного } \\
\text { здравоохранения, а также то, } \\
\text { как они приобретают все } \\
\text { большее и большее значение. } \\
\text { В этом процессе были приняты } \\
\text { теоретико-концептуальные } \\
\text { модели для объяснения того, } \\
\text { как социальные детерминанты } \\
\text { порождают неравенство в } \\
\text { отношении здоровья. }\end{array}$ \\
\hline $\begin{array}{l}\text { Статья } \\
\mathrm{XVI}\end{array}$ & $\begin{array}{l}\text { Saúde ambiental e } \\
\text { desenvolvimento na } \\
\text { Amazônia legal: } \\
\text { indicadores } \\
\text { socioeconômicos, } \\
\text { ambientais } \\
\text { sanitários, desafios e } \\
\text { perspectivas. }\end{array}$ & $\begin{array}{l}\text { Viana et al., } \\
\text { 2016, Brasil. }\end{array}$ & $\begin{array}{l}\text { Целью статьи было } \\
\text { обсуждение } \\
\text { социально-экологической } \\
\text { детерминации в государствах, } \\
\text { составляющих Легальную } \\
\text { Амазонку, на основе анализа } \\
\text { социально-экономических, } \\
\text { экологических и санитарных } \\
\text { показателей. }\end{array}$ \\
\hline $\begin{array}{l}\text { Статья } \\
\mathrm{XVII}\end{array}$ & $\begin{array}{l}\text { Saúde, ambiente e } \\
\text { desenvolvimento } \\
\text { econômico na } \\
\text { Amazônia. }\end{array}$ & $\begin{array}{l}\text { Vincentin e } \\
\text { Minayo, } \\
\text { 2003, Brasil. }\end{array}$ & $\begin{array}{l}\text { В исследовании } \\
\text { анализировался } \\
\text { трансформации } \\
\text { эпидемиологической картины } \\
\text { амазонского населения, } \\
\text { созданного для работы в } \\
\text { развитии Mineração Rio do Norte } \\
\text { S.A. (MRN), в муниципалитете } \\
\text { Оришимина }\end{array}$ \\
\hline
\end{tabular}

RC: 104519

Ссылка доступа: https://www.nucleodoconhecimento.com.br/здравоохранение/появлениеболезней 


\begin{tabular}{|c|c|c|c|}
\hline & & & $\begin{array}{l}\text { (РА), в местности Порто } \\
\text { Тромбетас. Определение } \\
\text { здоровья-болезненного } \\
\text { процесса разрабатывалось в } \\
\text { соответствии с конкретными } \\
\text { условиями социального } \\
\text { воспроизводства предприятия, } \\
\text { весьма отличными от условий } \\
\text { населения, связанного } \\
\text { традиционным } \\
\text { экономическим социально- } \\
\text { региона. }\end{array}$ \\
\hline $\begin{array}{l}\text { Статья } \\
\text { XVIII }\end{array}$ & $\begin{array}{l}\text { Deforestation, } \\
\text { Hunting and the } \\
\text { Ecology of Microbial } \\
\text { Emergence }\end{array}$ & $\begin{array}{l}\text { Wolfe, 2000, } \\
\text { Estados } \\
\text { Unidos. }\end{array}$ & 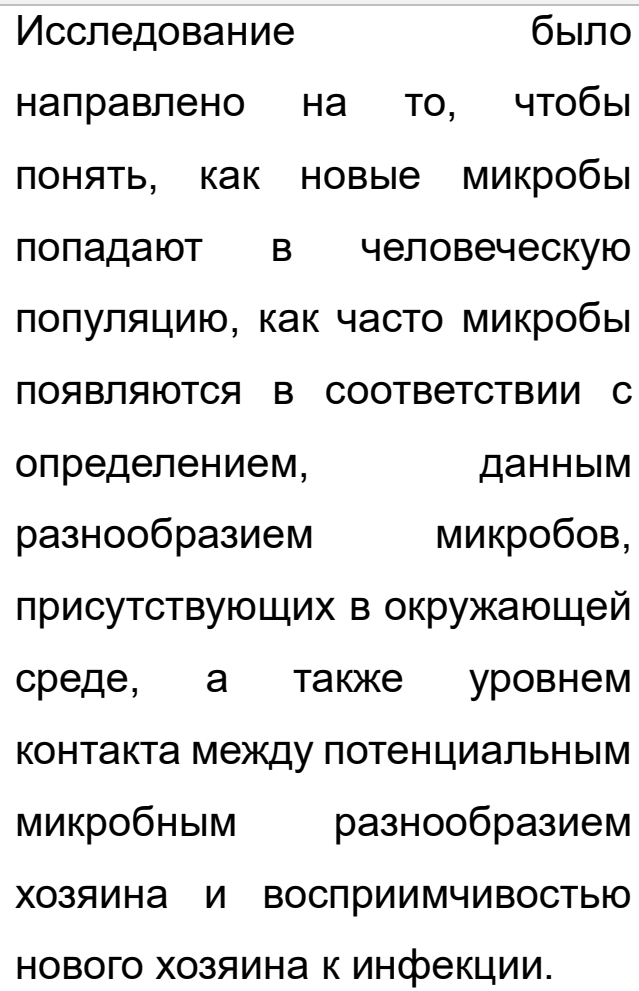 \\
\hline
\end{tabular}

Источник: собственные авторы.

Среди выбранных статей подавляющее большинство исследований показали, что экологические и социологические факторы, способствующие возникновению заболеваний в регионе Амазонки с 1970 года, как показано в статье «Chagas RC: 104519

Ссылка доступа: https://www.nucleodoconhecimento.com.br/здравоохранение/появлениеболезней 
disease and globalization of the Amazon» автора Briceño-Léon (2007), делают этот водосбор историческим. Такое изменение эпидемиологии заболеваний в регионе Амазонки можно объяснить экологическими и социальными изменениями за последние 30 лет, как поясняет автор.

Авторы Browder и Godfrey (2017), Browder и Godfrey (2017), Cardoso (2015), Carrapato и др. (2017), Confalonieri (2000), Confalonieri (2005), Medeiros (2014), Nobre (2004), Perz (2002), Sobral и Freitas (2010) и Viana et al. (2016) в своем опубликованном исследовании, в резюме, показал взаимосвязь социальных и экологических детерминант и их внутреннюю связь с процессом заболеваний здоровья различных групп населения, их значительную значимость для общественного здравоохранения и то, как они стали более заметными. В этом многолетнем процессе истории о том, что Амазонка столкнулась с социальными изменениями и фризико-территориального пространства, и как следствие обострением заболеваний, сконцентрированных в этом регионе.

\section{4. ОБЗОР И ОБСУЖДЕНИЕ ЛИТЕРАТУРЫ}

\section{1 РЕГИОНАЛЬНЫЕ АСПЕКТЫ}

Очень важным явлением в амазонской среде является взаимодействие между атмосферой и лесами, которые играют важную роль в производстве осадков в регионе. Климат, как правило, жаркий и влажный, а температура не сильно меняется, являясь важным регулятором биологических процессов, особенно тех, которые связаны с инфекционными заболеваниями (NOBRE, 2004).

Другой связанный с этим биофизический аспект связан с биоразнообразием, особенно разнообразием животных. Некоторые процессы очаговой инфекции в этой области, особенно процессы вирусной инфекции, зависят от кровососущих насекомых (переносчиков) для передачи (арбовирус). Чем больше разнообразие видов животных (позвоночных и беспозвоночных) в данной области, тем выше риск нового процесса заражения Wolfe (2000). Чтобы проиллюстрировать это, в 
Амазонии было идентифицировано около 196 арбовирусов, 32 из которых могут заражать людей (RODRIGUES, 2004).

Нобре (Nobre, 2004) отмечает, что применительно к амазонскому обществу можно выделить следующие важные демографические аспекты:

I. Низкая плотность населения региона (около 20 миллионов жителей на площади 3,5 миллиона квадратных километров) (INPE, 2013; IBGE, 2013);

II. высокие темпы роста, обеспечиваемые иммиграцией за последние 30 лет. Наблюдается также сильная межрегиональная миграция (PERZ, 2002);

III. города сильно сконцентрированы, особенно в столицах. Примерно $70 \%$ населения Амазонки живет в больших и малых городах. Характерно быстрое, спонтанное и беспорядочное появление многих из этих небольших городских поселений без необходимой санитарной инфраструктуры (BROWDER и GODFREY, 2017);

IV. существует большое количество традиционных популяций (индейцы, прибрежные жители, каучуковики и др.). которые живут на экстрактивизме и мелком сельском хозяйстве (INPE, 2013; IBGE, 2013).

Еще одна важная региональная особенность касается практики землепользования и ее экологических и социальных последствий. Некоторые из этих видов практики приводят к изменениям окружающей среды, которые представляют опасность для здоровья. Речь идет о загрязнении шахт ртутью; изза отсутствия санитарной инфраструктуры в городских районах вода загрязнена микроорганизмами; дым от горения после обезлесения вызывает проблемы с дыханием; локальные изменения в гидрологическом цикле, которые приводят к размножению комаров, чтобы перечислить лишь несколько более прямых последствий (CONFALONIERI, 2000).

Следует также помнить, что социальные конфликты, например, землевладение, приводят к насилию и культурным конфликтам, а также к резкому воздействию $\mathrm{RC}: 104519$

Ссылка доступа: https://www.nucleodoconhecimento.com.br/здравоохранение/появлениеболезней 
изолированных коренных народов и интродукции микробных агентов, ранее неизвестных этим общинам, что приводит к появлению новых заболеваний и увеличению числа случаев существующих в регионе (RODRIGUES, 2004).

Общим фоном этих событий является то, что политика в области развития и использования ресурсов игнорирует региональный потенциал, забывая об экологической устойчивости и экологической устойчивости Амазонки, не приводит к традиционной культуре или распределению доходов и не заботится о рисках для здоровья (CONFALONIERI, 2000).

На практике это происходит как по инициативе правительства, так и через реализацию крупных инфраструктурных проектов (автомагистрали, гидроэлектростанции и т.д.). и промышленность (коммерческая добыча), поощрение животноводства (и обезлесения), а также посредством спонтанной добывающей деятельности, такой, как добыча полезных ископаемых, рыболовство, лесозаготовки и другие (BRICEÑO-LEÓN, 2007; VICENTIN e MINAYO, 2003; FREITAS e GIATTI, 2009).

\section{2 СОЦИАЛЬНО-ЭКОЛОГИЧЕСКИЕ ПОКАЗАТЕЛИ}

В пространстве, которое окружает южную и восточную части Амазонки (штаты Рондония, Мату-Гросу, Токантинс, Мараньян и Пара), в последние годы активизировались вспышки пожаров, накопленная вырубка лесов и строительство автомагистралей, а также районы выращивания и интенсификации потребления пестицидов (INPE, 2013; IBGE, 2013).

Эти ресурсы были названы Nobre (2004) «дугой огня». Что касается потребления пестицидов, то показатели, достигнутые с этими веществами в регионе, были выразительными, составив 18\% от общенационального показателя. Согласно данным, опубликованным в 2009 году Бразильским институтом географии и статистики (IBGE), штат Мату-Гросу достиг самого высокого национального уровня использования пестицидов на гектар обрабатываемой площади в законной Амазонии (IBGE, 2013).

RC: 104519

Ссылка доступа: https://www.nucleodoconhecimento.com.br/здравоохранение/появлениеболезней 
Согласно рассмотренным показателям, данные об увеличении пахотных земель и пастбищ на природных территориях и кумулятивной вырубке лесов в Амазонии достигли самых высоких темпов в той же «дуге огня», с явной конвергенцией между расширением экстенсивного сельского хозяйства и обезлесением наряду с возникновением пожаров и использованием пестицидов (CARDOSO, 2015).

Следуя рассуждениям и спасению Confalonieri (2005), можно показать, насколько амазонские общества испытывают трудности в доступе к здравоохранению и, следовательно, отсутствие ухода и болезней. Автор обращает внимание на такие фракторы, как: низкая региональная демографическая плотность, значительный рост миграции, в том числе межрегиональных миграций, высокая концентрация городов, особенно в столицах, с отсутствием санитарной инфраструктуры и большим количеством традиционного населения, вредит социальным детерминантам в Амазонии, вызывая серьезные проблемы со здоровьем.

Для авторов Medeiros et al. (2014) также обсуждалась ситуация с условиями труда в районах природного и антропогенного ландшафта Амазонки. Это связано с тем, что условия и рабочая среда являются детерминантами профрессиональных заболеваний и классифицируются как неинфекционные заболевания. Поэтому здоровье работника концептуализируется как:

Um campo de saúde pública que tem como objeto de estudo e intervenção as relações produção-consumo e o processo saúde-doença. Neste campo, o trabalho é considerado como eixo organizador da vida social, espaço de dominação e resistência dos trabalhadores e determinantes das condições de vida e saúde das pessoas (BRASIL, 2018, p. 136).

Труд является важным фрактором, определяющим жизнь и здоровье людей. Зная, что в регионе Амазонки существует множество различных видов деятельности, отношений и условий обслуживания, важно, чтобы медицинские работники поощряли, предотвращали и диагностировали проблемы, связанные с задачами, выполняемыми в регионе Амазонки (CARDOSO, 2015). 
В этих весьма специфических профессиональных видах деятельности Амазонки, которые редки в других частях Бразилии, можно упомянуть: экстрактивизм растений - профессия, которая включает в себя, среди прочего, добывающий асаи, резиновый уплотнитель, сборщик бразильских орехов, пилоты пассажирских транспортных судов, старателей, рыбаков и многих других. Также считается, что крайне деградирующие трудовые отношения, которые во многих местах можно считать аналогом рабства, вполне очевидны в регионе из-за трудности контроля за большим расширением земель в Амазонии.

Поскольку это район, богатый рудой, старатели селятся в этом регионе и в охраняемых районах, где добыча запрещена. В результате проникновения в лесные районы как старатели, так и добытчики бразильских орехов и каучуков страдают от бактериальных заболеваний, передаваемых переносчиками или неинфекционными и простейшими, которые существуют в лесу.

Среди них можно отметить болезнь Шагаса, малярию, лейшманиоз и многие вирусные заболевания в регионе. Поэтому, учитывая большое число этих специалистов и риски, с которыми они сталкиваются, система здравоохранения должна направить действия таким образом, чтобы заболевания, прямо или косвенно связанные с работой, не стали фрактором повышенной заболеваемости и смертности в регионе Амазонки (CARDOSO, 2015).

Важно подчеркнуть, что дебаты о работе Амазонки и ее масштабах очень богаты, поскольку они также показывают, что Амазонка является местом, которое все еще является недавним местом конкретных исследований и политики общественного здравоохранения в отношении условий жизни, здоровьяболезней и работы в регионе (BENSABATH и SOARES, 2016).

\section{3 РЕГИОНАЛЬНЫЕ ЭПИДЕМИОЛОГИЧЕСКИЕ ПОКАЗАТЕЛИ}

Что касается региональных эпидемиологических показателей, то существуют некоторые важные различия между регионом Амазонки и остальной частью страны. В 1996 году уровень госпитализаций по инфекционным и паразитарным RC: 104519

Ссылка доступа: https://www.nucleodoconhecimento.com.br/здравоохранение/появлениеболезней 
заболеваниям был очень высоким (12,7\%), что намного выше, чем в среднем по стране (8,3\%). Хотя заболеваемость этими поражениями в Бассейне Амазонки снизилась, уровень смертности от этих заболеваний не был одинаковым (SUDAM, 2000).

Этот регион является домом для подавляющего большинства случаев малярии в стране (98\%), примерно 35\% случаев проказы в 2016 году и второй по величине заболеваемости туберкулезом среди всех регионов страны. Это также очень эндемичный район вирусного гепатита с частыми вспышками, особенно в западной части Амазонки (BENSABATH и SOARES, 2016).

Следует отметить, что в силу географических условий региона, а также процесса урбанизации и отсутствия базовой санитарии процессу вновь появились в Амазонии такие болезни, как холера в 1991 году и лихорадка денге в середине 1990-х годов, помимо этих, другие заболевания также вызывают большое число смертей среди населения региона, таких, как малярия, Лейшманиоз тегументарные американские паразитарные инфекции и особенно туберкулез (VIANA et al., 2016).

В литературе также раскрывается непропорциональная связь между улучшением качества жизни и ухудшением состояния окружающей среды, то есть развитие продвигается неустойчивым образом, и подчеркивается важность учета стоимости заболеваний, вызванных фракторами окружающей среды, которая возросла в регионе Амазонки (MEDEIROS et al., 2014).

Carrapato; Correa e Garcia (2017) сразу же связали качество жизни со здоровьем. Авторы подчеркивают, что, помимо биомедицинских моделей, существуют некоторые решающие фракторы, которые оказали или будут влиять на личное здоровье. Таким образом, эти детерминанты в настоящее время оказывают большее влияние на здоровье, чем те, которые в настоящее время охватываются медициной. Они подчеркнули существование трех детерминант: окружающей среды, экономики и общества, для них социальные детерминанты 
в значительной степени ответственны за несправедливость доступа к медицинскому обслуживанию.

\section{5. ВЫВОД}

Основываясь на ведущем вопросе исследования, можно сделать вывод, что основными фракторами окружающей среды, способствующими возникновению заболеваний в регионе Амазонки, являются вырубка лесов, сжигание, загрязнение рек, процесс урбанизации и агробизнес, тем самым делая вывод, что дискуссия об исследовании окончательно выявила некоторые вопросы, которые ответственны за количество заболеваний в Амазонке, где следует, например, рассмотреть географические, этнические, культурные и политические аспекты здравоохранения в регионе Амазонки. Отмечается, что отсутствует государственная политика, отвечающая спросу на болезни здоровья, связанные с социально-экологическими показателями региона, а также необходимость проведения дальнейших исследований и изысканий, с тем чтобы узнать о невзгодах, с которыми сталкиваются эти группы населения.

Также следует отметить, что основными экологическими факторами, способствующими возникновению заболеваний в регионе Амазонки, являются вырубка лесов, сжигание, загрязнение рек, процесс урбанизации и агробизнес, то есть все от действия человека.

Однако исследование также показывает, что с точки зрения экологических показателей здоровья и болезней амазонское пространство, сформированное взаимодействием социоэкологической системы, имеет отличные характеристики от других частей страны. Это различие обусловлено природным экологическим фундаментом и фрормами его занятия и развития. 


\section{ПЕРЕСМОТР БИБЛИОГРАФИЧЕСКИЙ}

\section{БЕНСАБАТ, Г. и СОАРЕС, М. до. Р. Эволюция знаний о вирусных гепатитах в} регионе Амазонки: от эпидемиологии и этиологии к профилактике. Rev. Soc. Bras. Med. Trop., 37(supl. II):14-36, 2016.

BRASIL. Ministério da Saúde. Secretaria de Atenção à Saúde. Secretaria de Vigilância em Saúde. Saúde do trabalhador e da trabalhadora [recurso eletrônico]. Cadernos de Atenção Básica, n. 41 - Brasília: Ministério da Saúde, 2018. 136 p.: il.

BRICEÑO-LEÓN, R. Chagas disease and globalization of the Amazon. Cadernos de Saúde Pública, Rio de Janeiro, v. 23, n. 53, p. 33-40, 2007. Suplemento 1.

BROWDER, J. O. e GODFREY, B. J. Rainforest Cities. Urbanization, Development and Colonization of the Brazilian Amazon. Columbia University Press, New York, 2017, 429 pp.

CAÑETE, T. M. R..; RAVENA-CAÑETE, V. Populações Tradicionais Amazônicas: revisando conceitos. In: V Encontro Nacional da Associação Nacional de PósGraduação e Pesquisa em Ambiente e Sociedade, 2010, Florianópolis Anais, V Encontro Nacional da Associação Nacional de Pós-Graduação e Pesquisa em Ambiente e Sociedade, 2010.

CARDOSO, A. C. M. O trabalho como determinante do processo saúde-doença. Tempo soc., São Paulo, v. 27, n. 1, p. 73-93, junho de 2015.

CARRAPATO, P.; CORREIA, P.; GARCIA, B. Determinante da saúde no Brasil: a procura da equidade na saúde. Saúde soc., São Paulo, v. 26, n. 3, p. 676- 689, Sept. 2017.

CONFALONIERI, U. E. C. (org.). The Health of Indigenous Peoples in the Brazilian Amazon. Background paper for the World Bank. Royal Tropical Institute, Amsterdam, 2000, 218 pp. 
CONFALONIERI, U. E. C. Saúde na Amazônia: um modelo conceitual para a análise de paisagens e doenças. Estud. av., São Paulo, v. 19, n. 53, p. 221-236, Apr. 2005.

FREITAS, C. M.; GIATTI, L. L. Indicadores de sustentabilidade ambiental e de saúde na Amazônia Legal. Cadernos de Saúde Pública, Rio de Janeiro, v. 25, n. 6 , p. 1251-1266, 2009.

IBGE - INSTITUTO BRASILEIRO DE GEOGRAFIA E ESTATíStICA. Contas nacionais: 2011. Rio de Janeiro, RJ, 2013.

INPE - Instituto Nacional De Pesquisas Espaciais. Monitoramento da floresta amazônica brasileira por satélite: 1988/2011. 2013.

MEDEIROS, M. S. de et al. Custo das doenças atribuíveis a fatores ambientais na cidade de Manaus, Amazonas, Brasil. Ciênc. Saúde coletiva [online]. 2014, vol.19, n.2, pp.599-608. 2014.

NOBRE, C. A. Recent Progress in Modeling Biome-Climate Interactions in Amazônia. Resumo 19.2. Anais III Conf. Cient.do LBA, 27-29 de julho, 2004. Brasília, DF, Cd-Rom.

PERZ, S. Population Growth and Net Migration in the Brazilian Legal Amazon, 1970- 1996, em WOOD e PORRO. Deforestation and Land Use in the Amazon. Gainesville, University Press of Florida, 2002, pp. 95-106.

RODRIGUES, S. G. Estudo dos arbovirus na Amazônia Brasileira. Em: Resumos do III Simpósio Internacional sobre Arbovirus nos Trópicos e Febres Hemorrágicas, Belém, Pará, 30/11 - 3/12, 2004. Instituto Evandro Chagas, 2004.

ROLIM, D. C. A pobreza e a riqueza na região amazônica e a contribuição da política de assistência social: o estado do amazonas em foco. VII Jornada Internacional de Políticas Públicas. Programa de Pós-graduação em políticas públicas. Universidade Federal do Maranhão, 2015. 
SOBRAL, A.; FREITAS, C. M. Modelo de organização de indicadores para operacionalização dos determinantes socioambientais da saúde. Saúde e Sociedade, São Paulo, v. 19, n. 1, p. 35-47. 2010.

SUDAM. Diagnóstico e cenarização macrossocial da Amazônia legal: perfil da saúde na Amazônia legal e o contexto brasileiro. Belém, Pnud, 2000, 54 p.

VIANA, Rosana Lima; FREITAS, Carlos Machado de; GIATTI, Leandro Luiz. Saúde ambiental e desenvolvimento na Amazônia legal: indicadores socioeconômicos, ambientais e sanitários, desafios e perspectivas. Saúde e Sociedade, v. 25, p. 233246, 2016.

VICENTIN, G.; МИНАЙО, К. G. Здравоохранение, окружающая среда и экономическое развитие в Амазонии. Наука и общественное здравоохранение, Рио-де-Жанейро, т. 8, № 4, стр. 1069-1085, 2003.

ВУЛФ, Н. Обезлесение, охота и экология возникновения микробов. Глобальные изменения и хм. Здоровье, 1(1):10-25, 2000.

Представлено: Декабрь 2021 год.

Утверждено: Декабрь 2021 год. 